\title{
Quality variations in the circular model of variety-differentiated products
}

\author{
Nicholas Economides* \\ Stern School of Business, New York University, New York, NY 10012-1126, USA
}

Received March 1989, final version received August 1991

\begin{abstract}
Quality variations are introduced in the circular model of differentiated products. Two main game structures are analyzed. The three-stage game has entry in the first stage, location in the second, and quality and price choice in the third. The four-stage game replaces the quality and price subgame of the three-stage game with two stages, quality choice followed by price choice. It is found that precommitment in quality (in the four-stage game) allows firms to support the same prices (as in the no-precommitment three-stage game) with lower quality levels and expenditure. This induces entry so that, at the free entry equilibrium, quality is lower and there is a larger number of brands in the precommitment game. In relation to optimality, both games result in higher diversity and under-provision of quality with bigger divergence from optimality observed in the four-stage precommitment game. Compared with a market without competition in quality, the equilibria with quality competition may result in a lower total surplus. A basic inverse relationship is established between the level of quality and the number of varieties at equilibrium. Thus, the establishment of minimum quality standards can reduce the number of varieties and increase total surplus.
\end{abstract}

\section{Introduction}

The circular model of variety-differentiated products [Salop (1979), Novshek (1980), Economides (1989a)] is augmented in the present work to include quality differentiation. ${ }^{1}$ In variety or horizontal (locational) differentiation, consumers differ in their most preferred variety. In quality (or vertical) differentiation all consumers desire more of the quality feature but they differ in the willingness to pay for improvements in quality. In the model developed in this paper each differentiated product is defined by one

Correspondence to: N. Economides, Stern School of Business, New York University, 4 West 4th Street, New York, NY 10012-1126, USA.

*I thank Barbara Katz, Susan Rose-Ackerman, Kelvin Lancaster, the editors, and an anonymous referee for helpful suggestions, and the participants of the Columbia Industrial Organization Workshop for their comments. Partial financial support from the National Science Foundation is gratefully acknowledged.

${ }^{1}$ Economides $(1986,1989 \mathrm{~b})$ and Neven and Thisse (1990) have recently developed models that combine horizontal and vertical product differentiation. After this paper's early version as 'Advertising in the Circular Model of Differentiated Products', Discussion paper no. 316, Department of Economics, Columbia University, David Waterman applied a similar approach to information products in Waterman (1990). 
feature of variety and one feature of quality. This facilitates the study of the effects of quality variations on such central questions as the over-abundance of varieties and the under-supply of quantities; specifically, this allows the exploration of the basic substitutability of variety for quality and the extent to which strategic interactions among firms define the variety-quality mix that the market provides.

Products are differentiated in two dimensions, one being the dimension of varietal (or horizontal) differentiation and the other being a dimension of quality (or vertical) differentiation. As an example of such a product line consider computers differentiated in variety by the task they perform best (because they are most suited to it) and also differentiated in quality by their speed. Consumers are differentiated according to tasks they want to perform on the computer, but they all prefer higher speed at the same price.

Attention is focused on quality features that are independent of marginal production costs. In the example concerning computers, all improvements in quality are assumed to come from better design of the computer and not to affect variable production costs. Another example of such a quality feature is advertising which typically does not affect variable production costs. ${ }^{2}$

The order of moves in the choice of variety, quality, and price will have an important effect on the properties of equilibrium. In many markets the order of moves is determined by technology and tradition. In others, it is up to the firms, and alternative game structures can emerge as equilibria. Traditionally the circular model of variety-differentiated products has been analyzed as a sequential game where firms enter in stage 1, locate in stage 2 , and choose prices in stage 3 . Stage 1 is interpreted as the long run, stage 2 as the medium run, and stage 3 as the short run. Introducing quality choices, two separate games that differ in the position of the choice of the level of quality are analyzed. First a game where quality and price decisions are taken simultaneously in the last stage of the game is discussed. This stage is preceded by the location stage, which is itself preceded by the entry stage. Equilibria are sought such that in each stage firms anticipate correctly the resulting actions in subsequent stages. Next a similar game is analyzed, where the last stage has been split in two stages, one of quality choice to be followed by a stage of price choice. The two game structures are illustrated in fig. 1 .

\footnotetext{
${ }^{2}$ Perception advertising enhances the perceived value of a product by attaching to varietydifferentiated commodities images that consumers value. The attached images have inherent value, i.e. are inherently desirable, but they need not have any immediate connection with the physical attributes of the product before attachment. It is assumed that the brands are trademarked so that it is possible to attach to the product a desired mental image which is irrelevant to its physical characteristics. Without a trademark the desired mental image would have to be attached to features of the product that can be imitated. Thus, it would be nearly impossible to compete in 'perception advertising' in a meaningful way. See Economides (1988).
} 

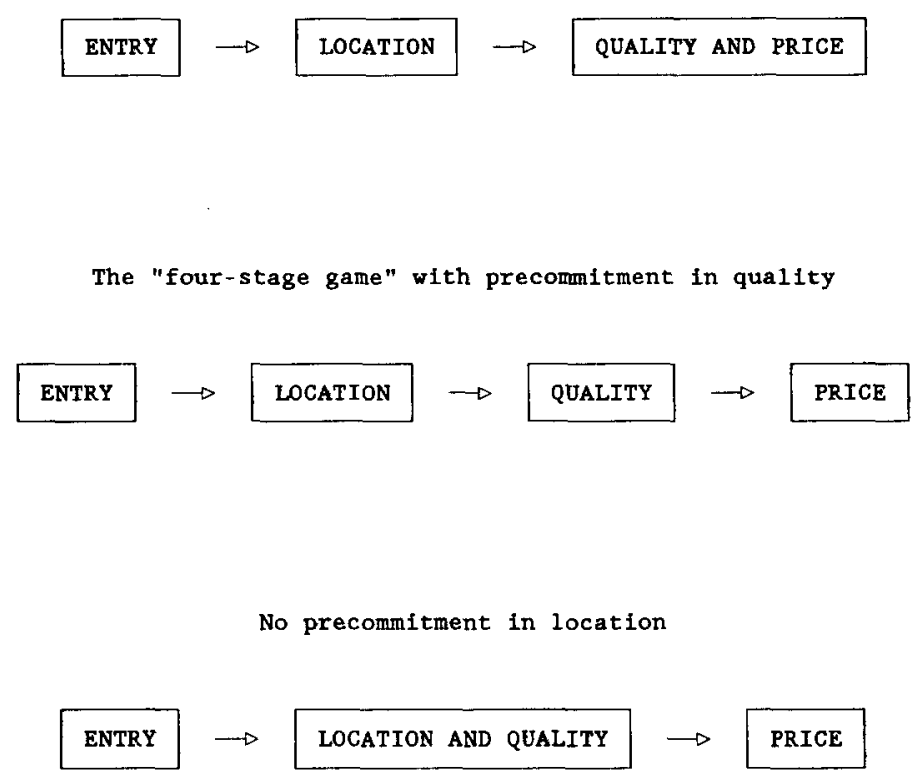

Fig. 1. The sequence of decisions in the game structures considered.

The use of these particular game structures is justified by the fact that all strategic variables are not equally flexible. In the very short run, only prices and perhaps some features of quality are flexible and therefore available as strategic variables. In the long run, product specification (location) is flexible, and in the very long run firms have the ability to enter and exit.

The two main game structures that will be analyzed differ in the position of the quality move in the game tree. Choice of quality earlier than price can be thought of as a 'pre-commitment' in quality. ${ }^{3}$ The effect of choice of quality at an earlier stage than price on the equilibrium quality is dependent on the response of prices of neighboring firms (in the price subgame) to changes in the quality of a firm. As we will see, quality is used as an aggressive strategic variable. When it is chosen at an earlier stage, each unit of quality has greater strategic value in securing extra revenue. Thus it is shown that firms will use smaller levels of quality when they have the opportunity to precommit in quality.

\footnotetext{
${ }^{3}$ Precommitment in advertising has been discussed in traditional settings by Nerlove and Arrow (1962) and more recently by Fudenberg and Tirole (1984) among others.
} 
In the medium run, with a fixed number of active firms, there are higher prices and higher profits in the game of precommitment. This implies a higher number of active firms in the long run free-entry equilibrium for the game of precommitment. Both games over-provide variety and under-provide quality, with the bigger distortion occurring under quality precommitment. ${ }^{4}$

A variation of the four-stage game so that there is no precommitment in locations is also briefly considered. The stages are entry, simultaneous choice of locations and quality levels, and choice of price. It is found that there is no difference between the equilibrium of this game and the one of the fourstage game with precommitment in locations. Because all locations are chosen simultaneously, there is no strategic advantage of locational precommitment.

In general, regulation of the number of varieties may be difficult. However, given the inverse relationship between the level of quality and the number of varieties, it is possible to reduce the number of varieties by increasing the level of quality. Furthermore, the under-provision of quality at equilibrium allows for the possibility that the creation of minimum quality standards is welfare-improving. Indeed it is shown that this is correct. It follows that, under conditions far from pathological, opening competition in quality can decrease total surplus.

The rest of the paper is organized as follows. Section 2 sets up the model. Section 3 establishes the equilibrium of the entry $\rightarrow$ location $\rightarrow$ (quality and price) game. Subsections establish the equilibrium in the subgames, starting from the last stage. Section 4 establishes the equilibrium of the entry $\rightarrow$ location $\rightarrow$ quality $\rightarrow$ price game. Section 5 compares the two equilibria. Section 6 discusses the social optimum and compares it with the long-run equilibria of the two previously discussed game structures. Section 7 discusses the effects on the long-run equilibrium and on social welfare of the

\footnotetext{
${ }^{4}$ There is no claim made that these are the only extensive forms worth considering. However, any game structure where locations are chosen in the last stage does not have a (subgame-perfect) equilibrium. The following argument is in the general spirit of Economides (1987). Consider an arbitrary quality-location-price configuration as a candidate non-cooperative equilibrium, where the prices after adjustment for quality differ, i.e. $p_{j}-\mathrm{E}(\theta) a_{j}<p_{j+1}-\mathrm{E}(\theta) a_{j+1}$. From two consecutive firms, choose the one with the lower price adjusted for quality, here firm $j$. Now consider a change of strategy by firm $j$ (from $x_{j}$ ) to location $x_{j+1}$. After the move, firm $j$ has at least half of its old demand (from old customers located between $x_{j}$ and $x_{j+1}$ ) plus at least the old demand of firm $j+1$. For a range of prices $p_{j}$ just below $p_{j+1}$ and for equal qualities $\left(q_{j}=q_{j+1}\right)$ this relocation strategy gives bigger profits to firm $j$ than its profits at its original position. Firm $j$ finds it profitable to make this move, and therefore for some price-quality combinations there is no non-cooperative equilibrium in the location subgame. This makes meaningless any discussion of choices in the earlier stages of the game, and equilibrium fails in the overall game. Note that, if prices were restricted to be equal whenever qualities were equal, the relocating strategy of firm $j$ would yield the same profits as before relocation and therefore would not pose problems for the equilibrium. The problem arises for the cases that violate this restriction that cannot be ruled out a priori.
} 
introduction of minimum quality standards and the restriction of competition in quality. Conclusions are presented in section 8 .

\section{Preliminaries}

A product is defined as a pair $\left(x_{j}, a_{j}\right)$, denoting its position in the variety and quality spaces, respectively. Varietal characteristic $x_{j}$ lies on a circumference of length 1 denoted by $C$. Quality level $a_{j}$ is chosen from the interval $[0, \bar{a}]$. The space of product characteristics is the cylinder $C \times[0, \bar{a}]$. A numeraire good, representative of all other goods in the economy, is also available to consumers.

Each consumer is defined by two parameters, $z$ and $\theta . z$ is interpreted as his/her most preferred variety and lies on $C$, the circumference of length $1 . \theta$ denotes the relative intensity of preference of each consumer for quality, and it lies in the interval $[0,1]$. The space of consumers' characteristics $(z, \theta)$ is the cylinder $C \times[0,1]$. The value to consumer $(z, \theta)$ of one unit of product $\left(x_{j}, a_{j}\right)$ sold at price $p_{j}$ is

$$
V\left(z, \theta, x_{j}, a_{j}, p_{j}\right)=k+\theta a_{j}-p_{j}-\left|z-x_{j}\right| .^{5}
$$

Note the separability of quality and variety in the utility function. It implies that increases in the level of quality of good $j$ are valued equally by consumers of the same intensity of desire for quality $\theta$, irrespective of their varietal preference. The units of $\theta$ and $a$ are normalized by assuming that $\theta$ is distributed on $[0,1]$ with cumulative distribution function $G(\theta)$.

Let firms $j=1, \ldots, n$ offer products $\left(x_{1}, a_{1}\right), \ldots,\left(x_{n}, a_{n}\right)$, respectively. Let the marginal consumer who is indifferent between products $\left(x_{j}, a_{j}\right)$ and $\left(x_{j+1}, a_{j+1}\right)$ be denoted by $z_{j}$. Then

$$
\begin{aligned}
& V\left(z_{j}, \theta, x_{j}, a_{j}, p_{j}\right)=V\left(z_{j}, \theta, x_{j+1}, a_{j+1}, p_{j+1}\right) \\
& \quad \Leftrightarrow z_{j}(\theta)=\left[p_{j+1}-p_{j}+x_{j+1}+x_{j}+\theta\left(a_{j}-a_{j+1}\right)\right] / 2 .
\end{aligned}
$$

Similarly, the marginal consumer between $\left(x_{j}, a_{j}\right)$ and $\left(x_{j-1}, a_{j-1}\right)$ is denoted by $z_{j-1} \cdot{ }^{6}$ Fig. 2 shows the locations of the marginal consumers $z_{j}(\theta)$ and $z_{j}{ }_{1}(\theta)$, in the space of consumers' characteristics $[0,1] \times C$. This cylindrical space has been opened up and is pictured as a parallelogram in fig. 2 for illustration purposes. The shaded region between lines $z_{j}(\theta)$ and $z_{j-1}(\theta)$

${ }^{5}$ The cost per unit of distance has been normalized to 1 without loss of generality.

${ }^{6} z_{j-1}$ is defined by

$$
\begin{aligned}
& V\left(z_{j-1}, \theta, x_{j}, a_{j}, p_{j}\right)=V\left(z_{j-1}, \theta, x_{j-1}, a_{j-1}, p_{j-1}\right) \\
& \quad \Leftrightarrow z_{j-1}(\theta)=\left[p_{j}-p_{j-1}+x_{j}+x_{j-1}+\theta\left(a_{j-1}-a_{j}\right)\right] / 2 .
\end{aligned}
$$




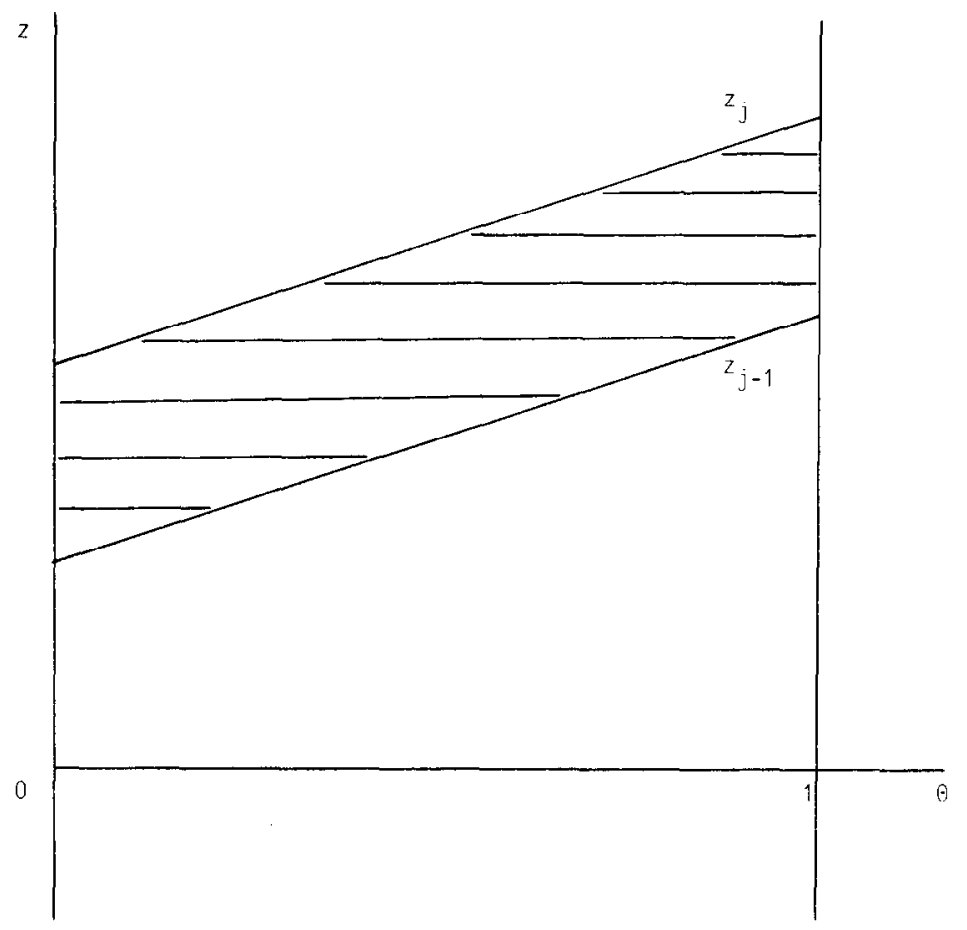

Fig. 2. The market area of firm $j$ in the space of characteristics.

represents consumers who prefer to buy product $\left(x_{j}, a_{j}\right)$ at the present prices. The demand for product $j$ is

$$
\begin{aligned}
D_{j} & =\int_{0}^{1} \int_{z_{j-1}}^{z_{j}} \mathrm{~d} z \mathrm{~d} G(\theta)=\int_{0}^{1}\left(z_{j}-z_{j-1}\right) \mathrm{d} G(\theta) \\
& =\left[p_{j+1}+p_{j-1}-2 p_{j}+x_{j+1}-x_{j-1}+\mathrm{E}(\theta)\left(2 a_{j}-a_{j+1}-a_{j-1}\right)\right] / 2,
\end{aligned}
$$

where $\mathrm{E}(\theta)=\int_{0}^{1} \mathrm{~d} G(\theta)$ is the expectation of $\theta$, i.e. the average intensity of preference for quality. The influence of quality on demand is increasing in the average intensity of preference for quality in the population, $\mathrm{E}(\theta) .^{\top}$

Assuming zero marginal production costs, convex costs of quality $C(a)=$ $c a^{2} / 2$, and a fixed cost $F$, firm $j$ has profit function ${ }^{8}$

${ }^{7}$ Note that $\mathrm{E}(\theta)$ lies in $[0,1]$ with its maximum attained when all consumers have the same very intense preference for quality.

${ }^{8}$ Of course, constant marginal costs lead to the same conclusions. The particular form of the cost function for quality is useful in getting closed-form results. 


$$
\Pi_{j}(\boldsymbol{p}, \boldsymbol{a}, \boldsymbol{x}, n)=p_{j} D_{j}(\boldsymbol{p}, \boldsymbol{a}, \boldsymbol{x}, n)-C\left(a_{j}\right)-F,
$$

where

$$
\boldsymbol{p}=\left(p_{1}, \ldots, p_{n}\right), \quad \boldsymbol{a}=\left(a_{1}, \ldots, a_{n}\right), \quad \boldsymbol{x}=\left(x_{1}, \ldots, x_{n}\right)
$$

are the $n$-tuples of strategies of prices, quality specifications, and variety specifications, respectively.

\section{The entry $\rightarrow$ location $\rightarrow$ (quality and price) game}

\subsection{The quality and price stage}

The analysis starts the last stage of the game. In this discussion, strategies will be restricted not to involve 'undercutting', where one or more firms is left with zero demand through the actions of opponents. This is because the aim of this paper is to focus on the effects of interaction of quality and variety rather than on problems of existence. Following Novshek (1980) it is assumed that, once undercut, a firm will respond by cutting its own price. Thus, undercutting strategies will never be used.

When the last stage of price and quality choice is reached, firms have already entered the industry and chosen locations. A particular price subgame is defined by the vector $\boldsymbol{x}$ of location choices already made. Maximizing profits of firm $j, \Pi_{j}$, with respect to its price $p_{j}$ implies

$$
\begin{aligned}
p_{j-1} / 4+p_{j}-p_{j+1} / 4= & \left(x_{j+1}-x_{j-1}\right) / 4+\mathrm{E}(\theta)\left(2 a_{j}-a_{j+1}-a_{j-1}\right) / 4 \equiv e_{j}, \\
& \text { for } j=1, \ldots, n .
\end{aligned}
$$

These $n$ conditions can be summarized as

$$
\boldsymbol{A} \cdot \boldsymbol{p}=\boldsymbol{y}+\mathrm{E}(\theta) \boldsymbol{H} \cdot \boldsymbol{a} \equiv \boldsymbol{e}(\boldsymbol{a}, \boldsymbol{y}),
$$

where

$$
\begin{aligned}
& \boldsymbol{A}_{j}=(0, \ldots, 0,-1 / 4,1,-1 / 4,0, \ldots, 0) \text { is the } j \text { th row of } \boldsymbol{A}, \\
& y_{j}=y_{j}(\boldsymbol{x})=\left(x_{j+1}-x_{j-1}\right) / 4 \text { is the } j \text { th row of } \boldsymbol{y}, \\
& \boldsymbol{H}_{j}=(0, \ldots, 0,-1 / 4,1 / 2,-1 / 4,0, \ldots, 0) \text { is the } j \text { th row of } \boldsymbol{H} .
\end{aligned}
$$

Note that both $\boldsymbol{A}$ and $\boldsymbol{H}$ are circulant $^{9}$ and symmetric matrices:

\footnotetext{
${ }^{9}$ In a circulant matrix each row is a shift by one position to the right of the row above it.
} 


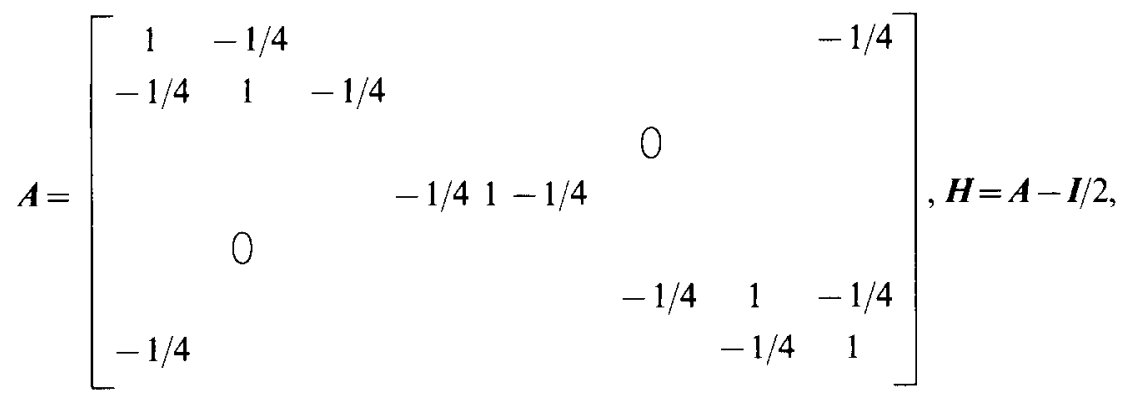

where $\boldsymbol{I}$ is the identity matrix. Note that $\boldsymbol{A}$ and $\boldsymbol{H}$ are matrices of constants. The variation of locations affects prices only through the vector $\boldsymbol{y}=\boldsymbol{y}(\boldsymbol{x})$.

Maximization of profits of firm $j, \Pi_{j}$, with respect to its quality level $a_{j}$ implies

$$
\mathrm{E}(\theta) p_{j}=c a_{j}, \quad j=1, \ldots, n .
$$

These $n$ condtions can be summarized as

$$
\mathrm{E}(\theta) \boldsymbol{p}=c \boldsymbol{a} .
$$

Together with the conditions from maximization with respect to prices, (1), they imply ${ }^{10}$

$$
\boldsymbol{c} \boldsymbol{A} \cdot \boldsymbol{a}^{*} / \mathrm{E}(\theta)=\boldsymbol{y}+\mathrm{E}(\theta) \boldsymbol{H} \cdot \boldsymbol{a}^{*} \Leftrightarrow \boldsymbol{a}^{*}=(\boldsymbol{c A} / \mathrm{E}(\theta)-\mathrm{E}(\theta) \boldsymbol{H})^{-1} \cdot \boldsymbol{y},
$$

Since both $\boldsymbol{A}$ and $\boldsymbol{H}$ are circulant symmetric matrices so is their linear combination $(c \boldsymbol{A} / \mathrm{E}(\theta)-\mathrm{E}(\theta) \boldsymbol{H}){ }^{11}$ The inverse of a circulant matrix exists if the sum of the elements of a row is non-zero. The sum of the elements of a row of $(c \boldsymbol{A} / \mathrm{E}(\theta)-\mathrm{E}(\theta) \boldsymbol{H})$ is $c /[2 \mathrm{E}(\theta)]$. Therefore its inverse $Q \equiv$ $(c \boldsymbol{A} / \mathrm{E}(\theta)-\mathrm{E}(\theta) H)^{1}$ exists for all $c>0$. The matrix $Q$ is circulant and symmetric because it is the inverse of a circulant, symmetric matrix. Thus, all elements of the main diagonal of $Q$ have the same value $q_{1}$; the value of all elements of the upper and lower diagonals is $q_{2}$, etc.

Combining eqs. (3) and (4), the equilibrium strategies in the price-quality subgame $\boldsymbol{a}^{* *}$ and $\boldsymbol{p}^{* *}$ can be expressed as functions of the vector $\boldsymbol{x}$ :

\footnotetext{
${ }^{10}$ The second-order conditions are

$$
\partial^{2} \Pi_{j} / \partial p_{j}^{2}=-2<0, \quad \partial \Pi_{j}^{2} / a_{j}^{2}=-c<0,
$$

and$$
0<\left(\partial^{2} \Pi_{j} / \partial p_{j}^{2}\right)\left(\partial^{2} \Pi_{j} \partial a_{j}^{2}\right)-\left(\partial^{2} \Pi_{j} / \partial p_{j} \partial a_{j}\right)^{2}=2 c-(\mathrm{E}(\theta))^{2},
$$

i.c. $c>(\mathrm{E}(\theta))^{2} / 2$.

${ }^{11}$ Multiplying $\boldsymbol{A}$ and $\boldsymbol{H}$ with scalars produces two circulant matrices. Their sum is also a circulant matrix.
} 


$$
\begin{aligned}
& a^{*}(x, n)=Q \cdot y(x)=(c A / \mathrm{E}(\theta)-\mathrm{E}(\theta) H)^{-1} \cdot y(x), \\
& p^{*}(x, n)=c a^{*} / \mathrm{E}(\theta)
\end{aligned}
$$

Realized profits when the equilibrium strategies are used in the subgame are

$$
\Pi_{j}\left(\boldsymbol{p}^{*}(\boldsymbol{x}, n), \boldsymbol{a}^{*}(\boldsymbol{x}, n), \boldsymbol{x}, n\right)=c^{2}\left[a_{j}^{*}(\boldsymbol{x}, n)\right]^{2}\left[1 / \mathrm{E}(\theta)^{2}-1 /(2 c)\right]-F .
$$

\subsection{The location stage}

In stage 2, firms choose locations expecting to receive the profits of the implied equilibrium of the quality and price subgame. Thus the objective function of firm $j$ in the stage of the choice of locations is

$$
\Pi_{j}^{\mathrm{L}}(\boldsymbol{x}, n)=\Pi_{j}\left(p^{*}(\boldsymbol{x}, n), a^{*}(\boldsymbol{x}, n), \boldsymbol{x}, n\right),
$$

which is given by (6) above. The rate of change of profits with respect to location can be directly calculated as

$$
\mathrm{d} \Pi_{j}^{\mathrm{L}} / \mathrm{d} x_{j}=2 c^{2} a_{j}^{*}\left[1 / \mathrm{E}(\theta)^{2}-1 /(2 c)\right] \mathrm{d} a_{j}^{*} / \mathrm{d} x_{j} .
$$

From (5), the rate of change of equilibrium quality with location is

$$
\mathrm{d} a_{j}^{*} / \mathrm{d} x_{j}=\sum_{i=}^{n / 2} q_{n / 2}\left(1+|i| d y_{j+i} / \mathrm{d} x_{j}\right)=\left(q_{2}-q_{2}\right) / 4=0,
$$

because $\mathrm{d} y_{j+1} / \mathrm{d} x_{j}=q_{2} / 4, \mathrm{~d} y_{j+1} / \mathrm{d} x_{j}=-q_{2} / 4$, and $\mathrm{d} y_{i} / \mathrm{d} x_{j}=0$, for $i \neq j+1$, $j-1$. Therefore a symmetric equilibrium $x^{*}(n)$ of the locations' choice stage exists with $x_{j}^{*}(n)-x_{j-1}^{*}(n)=1 / n$, for all $j .^{12}$ The implied equilibrium values of prices and qualities are found by substitution in (5):

$$
p_{j}^{*}\left(\boldsymbol{x}^{*}(n)\right)=1 / n, \quad a_{j}^{*}\left(\boldsymbol{x}^{*}(n)\right)=\mathrm{E}(\theta) /(c n) .
$$

The distance between neighboring firms gives a rough measure of the potential demand for each firm. Quality, an aggressive strategic variable, is used in proportion with potential gain. Thus, the optimal quality level $a_{j}^{*}$ in eq. (8) is increasing in the distance between firms, $1 / n$. As the number of firms increases, the incentive to provide high-quality levels falls because the

\footnotetext{
${ }^{12}$ The level of quality and profits of firm $j$ remains unaffected by small changes in the variety specification for a range of varietal positions. This is an artifact of the linear model with inelastic demand, noticed before by Novshek (1980) in variation of profits with variety in a model without quality variation. A shift of the location of firm $j$ to the left results in a gain of as many consumers on the right of the firm as a loss of consumers on the left. The introduction of some elasticity of demand will easily pinpoint the middle-point variety as the one that maximizes profits.
} 
potential market for capture by each firm falls. Thus, the level of quality and the number of varieties are inversely related.

The realized profits at the location stage with $n$ firms in competition are

$$
\begin{aligned}
\Pi_{j}^{\mathrm{L}}\left(\boldsymbol{x}^{*}(n), n\right) & =\Pi_{j}\left(\boldsymbol{p}^{*}\left(\boldsymbol{x}^{*}(n), n\right), \boldsymbol{a}^{*}\left(\boldsymbol{x}^{*}(n), n\right), \boldsymbol{x}^{*}(n), n\right) \\
& =\left[1-\mathrm{E}(\theta)^{2} /(2 c)\right] / n^{2}-F .
\end{aligned}
$$

Quality is an aggressive strategic variable used by firms to secure their share in a market of fixed total demand. When consumers are willing to pay more for quality, and $\mathrm{E}(\theta)$ increases, firms respond by producing goods of higher quality and seeking customers more aggressively. This increases costs and decreases profits for each firm. Thus, the realized profits are decreasing in the average intensity of preference for quality, $\mathrm{E}(\theta)$.

\subsection{The entry and exit stage}

Finally, in stage 1 firms choose to enter or not in the industry. The objective function of a firm that enters the industry is

$$
\Pi_{j}^{\mathrm{E}}(n) \equiv \Pi_{j}^{\mathrm{L}}\left(\boldsymbol{x}^{*}(n), n\right),
$$

as given by (9) above. Assuming zero profits outside the industry, the free-entry equilibrium number of firms is the integer part of

$$
n^{*}=\left\{\left[1-\mathrm{E}(\theta)^{2} /(2 c)\right] / F\right\}^{1 / 2} .
$$

which makes profits zero, $\Pi_{j}^{\mathrm{E}}\left(n^{*}\right)=0$. In what follows, the superscript $3 \mathrm{~s}^{*}$ denotes the full equilibrium of the three-stage (entry $\rightarrow$ location $\rightarrow$ quality and price) game:

$$
\begin{aligned}
& p_{j}^{3 \mathrm{~s}^{*}}=1 / n^{3 \mathrm{~s}^{*}}, \quad a_{j}^{3 \mathrm{~s}^{*}}=\mathrm{E}(\theta) /\left(c n^{3 \mathrm{~s}^{*}}\right), \\
& n^{3 \mathrm{~s}^{*}}=\left\{\left[1-\mathrm{E}(\theta)^{2} /(2 c)\right] / F\right\}^{1 / 2}
\end{aligned}
$$

Theorem 1. The three-stage game of entry choice in the first stage, location choice in the second stage, and quality and price choice in the third stage has a symmetric equilibrium $\left(\boldsymbol{p}^{3 \mathrm{~s}^{*}}, \boldsymbol{a}^{3 \mathrm{~s}^{*}}, \boldsymbol{x}^{3 \mathrm{~s}^{*}}, n^{3 \mathrm{~s}^{*}}\right)$ given by eqs. $(10 a)$ and $(10 b)$.

In the present subsection it was established that increases in the average intensity of preference for quality, $\mathrm{E}(\theta)$, resulted in higher quality levels and lower profits when the number of firms was fixed. In the long run, with the number of firms flexible and profits approximately zero, increases in the intensity of preferences for quality results in a smaller number of firms at 
equilibrium. This gives an added boost to the level of quality in the long run. Equilibrium quality, $a_{j}^{*}\left(x^{*}(n)\right)$, was increasing in $\mathrm{E}(\theta)$ even when the number of firms was fixed, as in eq. (8); in the long run increases in $\mathrm{E}(\theta)$ decrease the active number of firms $n^{33^{*}}$. This causes an added increase in the quality level $a_{j}^{3 \mathrm{~s}^{*}}$.

Corollary 1. An increase in the average intensity of preference for quality results in an increase in the level of quality and a decrease in the number of varieties offered at equilibrium.

An observation regarding symmetry is in order. Note that, since prices are proportional to quality levels [from eq. (3)], symmetric locations imply [from eq. (5)] equal prices, equal quality levels, and equal profits. Asymmetric locations would imply unequal prices, quality levels, and profits. A higher potential market area for firm $j, x_{j+1}-x_{j-1}>1 / n$, implies a higher quality level, price, and profits for firm $j$. Let the free-entry equilibrium be defined by a zero-profit condition for the firm that makes the lowest profits. Then all other firms are making positive profits and correspond to market areas larger than $1 / n$. Since the sum of the market areas is 1 , an asymmetric equilibrium involves a (weakly) smaller number of firms than a symmetric one. The over-abundance of varieties established later in Corollary 4 could be reversed in an asymmetric cquilibrium.

Note that a maintained assumption throughout this paper is that each firm offers only one variety-price combination. In particular, this rules out a firm producing two products of different quality levels but of the same location (variety). Thus, the issue of relaxing competition through quality differentiation as well as the issue of finiteness of the number of products of different quality levels that can co-exist in a market in the context of a 'natural oligopoly' raised by Jaskold-Gabszewicz and Thisse (1980) and Shaked and Sutton (1983) do not arise.

\section{The entry $\rightarrow$ location $\rightarrow$ quality $\rightarrow$ price game}

In this section, a four-stage game where entry, location, quality, and price are chosen sequentially is analyzed. Splitting the quality-price subgame into two stages, a stage of quality choice followed by a stage of price choice, allows for effective communication of the choices of quality levels before the choice of prices. In the four-stage game, the choice of quality can be thought of as a commitment because it allows players to reveal how aggressively they are willing to compete before prices are chosen. Communication accentuates the value of quality as an aggressive stategic variable. Firms can now utilize a lower level of the aggressive strategic variable, quality, to achieve the same 
results. Thus, starting with the same number of symmetrically located firms, we expect the level of quality to be lower at the equilibrium of the two-stage (quality $\rightarrow$ price) subgame than at the subgame of simultaneous quality-price choice that we analyzed above.

\subsection{The price stage}

At the stage of price choice, the number of firms and the location and quality choices of all firms have already been chosen in previous stages and are considered given and fixed. A particular price subgame is defined by the vector $(\boldsymbol{a}, \boldsymbol{x}, n)$ of choices already made. Maximization of profits of firm $j, \Pi_{j}$, with respect to its price $p_{j}$ implies

$$
\begin{aligned}
p_{j-1} / 4+p_{j}-p_{j+1} / 4= & \left(x_{j+1}-x_{j-1}\right) / 4+\mathrm{E}(\theta)\left(2 a_{j}-a_{j+1}-a_{j-1}\right) / 4 \equiv e_{j}, \\
& \text { for } j=1, \ldots, n
\end{aligned}
$$

These conditions can be summarized as before as

$$
\boldsymbol{A} \cdot \boldsymbol{p}=\boldsymbol{y}+\mathrm{E}(\theta) \boldsymbol{H} \cdot \boldsymbol{a} \equiv \boldsymbol{e}(\boldsymbol{a}, \boldsymbol{y})
$$

and can be solved to determine equilibrium prices in the subgame

$$
p^{* *}(a, x, n)=A^{-1}(y(x)+\mathrm{E}(\theta) H \cdot a) \equiv A^{-1} \cdot e(a, x) .
$$

Since $A$ is a circulant matrix and the sum of the elements of any of its rows is $1 / 2 \neq 0$, the inverse of $\boldsymbol{A}$ exists and it is a circulant matrix $\boldsymbol{B} \equiv \boldsymbol{A}^{-1}$. Since $\boldsymbol{B}$ is circulant, all elements in a diagonal of $\boldsymbol{B}$ are equal. Let the element of the diagonal of distance $i$ from the main diagonal be $b_{1+i}$. Then the equilibrium price of firm $j$ in the price subgame follows from (11):

$$
p_{j}^{* *}=\sum_{i--n / 2}^{n / 2} b_{1+|i|} e_{j+i}(\boldsymbol{a}, \boldsymbol{x})
$$

The realized profits at equilibrium are

$$
\Pi_{j}\left(\boldsymbol{p}^{* *}(\boldsymbol{a}, \boldsymbol{x}, n), \boldsymbol{a}, \boldsymbol{x}, n\right)=\left(p_{j}^{* *}\right)^{2}-c\left(a_{j}\right)^{2} / 2-F .
$$

\subsection{The stage of quality choice}

At the stage of quality choice, the number of firms and their locations have been already chosen as $(x, n)$. Firms expect that in the subsequent stage 
of price determination the non-cooperative equilibrium $p^{* *}(a, x, n)$ will result. Firms take this into account by using in their objective functions at this stage the equilibrium prices defined parameterically as functions of their quality choices:

$$
\Pi_{j}^{\mathrm{A}}(\boldsymbol{a}, \boldsymbol{x}, n) \equiv \Pi_{j}\left(\boldsymbol{p}^{* *}(\boldsymbol{a}, \boldsymbol{x}, n), \boldsymbol{a}, \boldsymbol{x}, n\right)=\left(p_{j}^{* *}\right)^{2}-c\left(a_{j}\right)^{2} / 2-F .
$$

Maximization of profits, $\Pi_{j}^{\mathrm{A}}$, by firm $j$ with respect to its level of quality, $a_{j}$, implies

$$
c a_{j}^{* *}=2 p_{j}^{* *}\left(\mathrm{~d} p_{j}^{* *} / \mathrm{d} a_{j}\right), \quad j=1, \ldots, n .
$$

From eq. (12) one can derive the rate of change of prices with respect to quality at the equilibrium of the price subgame as

$$
\mathrm{d} p_{j}^{* *} / \mathrm{d} a_{j}=\sum_{i=-n / 2}^{n / 2} b_{1+|i|} \mathrm{d} e_{j+1} / \mathrm{d} a_{j} .
$$

Since $\mathrm{d} e_{j} / \mathrm{d} a_{j}=\mathrm{E}(\theta) / 2, \mathrm{~d} e_{j-1} / \mathrm{d} a_{j}=-\mathrm{E}(\theta) / 4$, and $\mathrm{d} e_{j+1} / \mathrm{d} a_{j}=-\mathrm{E}(\theta) / 4$, while $\mathrm{d} e_{j+i-1} / \mathrm{d} a_{j}=0$ for $i \neq 0,1,2$, it follows that

$$
\mathrm{d} p_{j}^{* *} / \mathrm{d} a_{j}=\mathrm{E}(\theta)\left(b_{1}-b_{2}\right) / 2 .
$$

Combining (14) and (15) it follows that the equilibrium level of quality is proportional to the equilibrium level of price, $a_{j}^{* *}=\mathrm{E}(\theta)\left(b_{1}-b_{2}\right) p_{j}^{* *} / c$, which can be written in vector form as

$$
c a^{* *}=\mathrm{E}(\theta)\left(b_{1}-b_{2}\right) p^{* *}{ }^{13}
$$

Eliminating $p^{*}$ between (1) and (16) we have the equilibrium level of quality $^{14}$

$$
\boldsymbol{a}^{* *}(\boldsymbol{x}, n)=\mathrm{E}(\theta)\left(b_{1}-b_{2}\right)\left(c \boldsymbol{A}-\mathrm{E}(\theta)^{2}\left(b_{1}-b_{2}\right) \boldsymbol{H}\right)^{-1} \cdot \boldsymbol{y}(\boldsymbol{x}) .
$$

The matrix $\left(c \boldsymbol{A}-\mathrm{E}(\theta)^{2}\left(b_{1}-b_{2}\right) \boldsymbol{H}\right)$ is symmetric and circulant becausc it is a linear combination of symmetric circulant matrices. The sum of the elements of any of its rows is $c / 2$. Therefore its inverse exists for all $c>0$. 'Thus an equilibrium exists in the stage of quality choice for any positive quality costs. The implied equilibrium prices $p^{* *}\left(a^{* *}(x, n), x, n\right)$ are found by

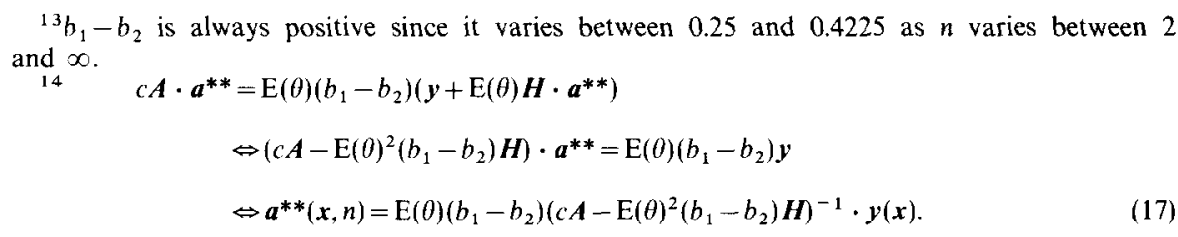


substitution in (12) of the equilibrium levels of quality given by (17). The resulting equilibrium profits in the stage of quality choice are

$$
\Pi_{j}^{\mathrm{A}}\left(\boldsymbol{a}^{* *}(\boldsymbol{x}, n), \boldsymbol{x}, n\right)=c\left\{c /\left[\left(b_{1}-b_{2}\right)^{2} \mathrm{E}(\theta)^{2}\right]-1 / 2\right\}\left[a_{j}^{* *}(\boldsymbol{x}, n)\right]^{2}-F .
$$

\subsection{The stage of location (variety) choice}

At the stage of the choice of locations (varieties) only the number of active firms in the industry has already been determined. Firms anticipate the equilibrium $\left(\boldsymbol{a}^{* *}(\boldsymbol{x}, n), \boldsymbol{p}^{* *}\left(\boldsymbol{a}^{* *}(\boldsymbol{x}, n), \boldsymbol{x}, n\right)\right)$ that will result in the subgame that starts with the choice of quality. At the slage of location choice, the objective function of firm $j$ is

$$
\Pi_{j}^{\mathrm{L}}(\boldsymbol{x}, n) \equiv \Pi_{j}^{\mathrm{A}}\left(\boldsymbol{a}^{* * *}(\boldsymbol{x}, n), \boldsymbol{x}, n\right),
$$

i.e. the equilibrium profits of the quality stage as given by (18).

Inspecting (18), we see that the derivative of profits, $\Pi_{j}^{\mathrm{L}}$, with respect to location $x_{j}$ is proportional to $\mathrm{d} a_{j}^{* *} / \mathrm{d} x_{j}$. Since $\left[c \boldsymbol{A}-\mathrm{E}(\theta)^{2}\left(b_{1}-b_{2}\right) \boldsymbol{H}^{-1}\right]$ is symmetric and circulant, $\mathrm{d} a_{j}^{* *} / \mathrm{d} x_{j}=0$ at symmetric locations, using the same reasoning as in subsections 3.2 and 4.1 . Therefore a symmetric equilibrium $x^{* *}(n), x_{j}^{* *}-x_{j-1}^{* *}=1 / n$, exists in the subgame that starts with the choice of locations.

The implied prices, quality levels, and profits are found by substitution in (16)-(18):

$$
\begin{aligned}
& p_{j}^{* *}(n)=p_{j}^{* *}\left(a^{* *}\left(x^{* *}, n\right), x^{* *}, n\right)=1 / n, \\
& a_{j}^{* *}(n)=a_{j}^{* *}\left(x^{* *}, n\right)=\mathrm{E}(\theta)\left(b_{1}-b_{2}\right) /(c n), \\
& \Pi_{j}^{\mathrm{L}}\left(x^{* *}(n), n\right)=\left[1-\mathrm{E}(\theta)^{2}\left(b_{1}-b_{2}\right)^{2} /(2 c)\right] / n^{2}-F .
\end{aligned}
$$

By comparing this equilibrium with the symmetric location equilibrium of the three-stage game [eqs. (8)-(9)] we see that for the same number of firms (same distance between firms) the prices are the same, quality is lower, and profits are higher in the present game. ${ }^{15}$ Quality has a higher strategic value when precommitment is allowed. Thus precommitment in quality in the present game allows firms to achieve the same prices and revenues while reducing quality levels and costs. Therefore overall profits improve when precommitment is allowed.

Lemma 1. When the same number of firms are active, the level of quality is lower and profits are higher in the four-stage (precommitment) game than in the three-stage game.

$$
{ }^{15} a^{*}(n)<a^{* *}(n) \Leftrightarrow \mathrm{E}(\theta)\left(b_{1}-b_{2}\right) d / c<\mathrm{E}(\theta) d / c \Leftrightarrow b_{1}-b_{2}<1, \text { true. }
$$




\subsection{The entry stage}

In the first stage of the game, which is interpreted as the very long run, firms decide whether to enter the industry. The objective function of a firm that decides to be active in the industry is $\Pi_{j}^{\mathrm{E}}(n)=\Pi_{j}^{\mathrm{E}}\left(x^{* *}(n), n\right)$ given by (19c). If the firm decides to stay inactive, it makes zero profits. Since $\Pi_{j}^{\mathrm{E}}(n)$ is decreasing in $n$, there is a unique number of firms that makes the profits of every active firm zero:

$$
n^{4 s^{*}}=\left\{\left[1-\mathrm{E}(\theta)^{2}\left(b_{1}-b_{2}\right)^{2} /(2 c)\right] / F\right\}^{1 / 2} .
$$

The equilibrium number of firms is the integer part of $n^{4 s^{*}}$.

The implied equilibrium values for locations qualities and prices are

$$
\begin{aligned}
& x_{j}^{4 \mathrm{~s}^{*}}-x_{j-1}^{4 \mathrm{~s}^{*}}=1 / n^{4 \mathrm{~s}^{*}}, \quad a^{4 \mathrm{~s}^{*}} \equiv a_{j}^{*}\left(x^{*}\left(n^{4 \mathrm{~s}^{*}}\right), n^{4 \mathrm{~s}^{*}}\right)=\mathrm{E}(\theta)\left(b_{1}-b_{2}\right) /\left(c n^{4 \mathrm{~s}^{*}}\right), \\
& p_{j}^{4 \mathrm{~s}^{*}} \equiv p_{j}^{* *}\left(a^{* *}\left(x^{* *}\left(n^{4 \mathrm{~s}^{*}}\right), n^{4 \mathrm{~s}^{*}}\right), x^{* *}\left(n^{4 \mathrm{~s}^{*}}\right), n^{4 \mathrm{~s}^{*}}\right)=1 / n^{4 \mathrm{~s}^{*}}
\end{aligned}
$$

Theorem 2. The four-stage game with entry in the first stage, location choice in the second stage, quality level choice in the third stage, and price choice in the fourth stage, has an equilibrium number of active firms $n^{4 \mathrm{~s}^{*}}=$ $\left\{\left[1-\mathrm{E}(\theta)^{2}\left(b_{1}-b_{2}\right)^{2} /(2 c)\right] / F\right\}^{1 / 2}$, symmetric locations at distances $d^{4 \mathrm{~s}^{*}}=1 / n^{4 \mathrm{~s}^{*}}$ apart, quality $a^{4 \mathrm{~s}^{*}}=\mathrm{E}(\theta)\left(b_{1}-b_{2}\right) /\left(c n^{4 \mathrm{~s}^{*}}\right)$, and price level $p^{4 \mathrm{~s}^{*}}=1 / n^{4 \mathrm{~s}^{*}}$.

\section{Comparisons}

In comparison with the three-stage game, we see that the four-stage game has a larger number of products (varieties) at equilibrium, $n^{4 s^{*}}>n^{3 s^{*}}$. As a result of the availability of precommitment in quality, profits are higher for any given number of firms and therefore at the long-run equilibrium more firms enter the industry in the four-stage game than in the three-stage game.

Corollary 2. The long-run equilibrium number of varieties in the four-stage game with quality precommitment is larger than in the three-stage game without precommitment.

Comparing the overall equilibrium of the four-stage game with the three-stage one, we see that in the four-stage game prices and quality levels are lower. The availability of precommitment in quality gives firms a strategic advantage in the quality stage and in subsequent stages of the game over a game of no precommitment. As we saw above, for a fixed number of active firms, $n$, a firm in the four-stage game is able to achieve the same revenue as in the three-stage game, but with a lower quality level and costs thereof. However, in the overall game, the strategic advantage mechanism has further consequences. More firms enter when precommitment is avail- 
able. As a result, prices and revenues fall in the subgames that are now more competitive since they are now played by a larger number of firms. The level of quality falls further since it now has to support lower prices. Crowding of firms in the commodity space lowers prices and results in an even lower quality level in the overall equilibrium with precommitment.

Corollary 3. The level of quality in the four-stage game is lower than in the three-stage game, $a^{4 \mathrm{~s}^{*}}<{ }^{3 \mathrm{~s}^{*}}$.

Also note that the lack of precommitment in the choice of locations does not have an effect on the equilibrium. Consider the game structure of entry in the first stage, location and quality choice in the second stage, and price choice in the last stage, i.e. the entry $\rightarrow$ (location and quality) $\rightarrow$ price game. It differs from the game structure of scction 4 in one respect only, that is in the collapsing of the choice of locations and the choice of qualities in one stage. It is not difficult to show that the equilibrium of these two game structures is identical. ${ }^{16}$ Intuitively, the simultaneous choice of locations does not convey any strategic threat, so it does not affect the equilibrium.

It has been shown that precommitment reduces the quality levels while increasing the number of brands. The welfare comparison between the equilibrium of these two games is a priori unclear since both higher quality and a larger number of varieties are desirable. These comparisons are made in the next section after the discussion of the surplus maximizing solution.

\section{Optimality}

The total surplus generated by one firm when there are $n$ firms each at

${ }^{16}$ The realized profits in the price subgame are given by eq. (13):

$$
\Pi_{j}\left(p^{* *}(a, x, n), a, x, n\right)=\left(p_{j}^{* *}\right)^{2}-c\left(a_{j}\right)^{2} / 2-F .
$$

In the stage of quality and location choice, maximization with respect to quality is characterized by eq. (16):

$$
c a^{* *}=\mathrm{E}(\theta)\left(b_{1}-b_{2}\right) p^{* *} .
$$

Maximization with respect to locations is characterized by

$$
\mathrm{d} \Pi_{j} / \mathrm{d} x_{j}=2 p_{j}\left(\mathrm{~d} p_{j}^{* *} / \mathrm{d} x_{j}\right)=0 .
$$

Now,

and

$$
\begin{aligned}
& p_{j}^{* *}=\sum_{i=-n / 2}^{n / 2} b_{1+|i|} e_{j+i}(\boldsymbol{a}, \boldsymbol{x}), \\
& e_{j}=\left(x_{j+1}-x_{j-1}\right) / 4+\mathrm{E}(\theta)(\boldsymbol{H} \cdot \boldsymbol{a})_{j},
\end{aligned}
$$

Therefore

$$
\mathrm{d} e_{j} / \mathrm{d} x_{j}=0, \quad \mathrm{~d} e_{j+1} / \mathrm{d} x_{j}=-1 / 4, \quad \mathrm{~d} e_{j-1} / \mathrm{d} x_{j}=1 / 4 .
$$

$$
\mathrm{d} p_{j}^{* *} / \mathrm{d} x_{j}=-b_{2} / 4+b_{2} / 4=0 .
$$

Since it is characterized by the same conditions, it follows that the equilibrium of this game is identical to the one of the game of sequential choice of locations, quality levels, and prices, $(4 \mathrm{~s})$. 
distance $1 / n$ apart from its immediate neighbors and they all sell quality $a$ at price $p$ is

$$
\begin{aligned}
s(n) & =2 \int_{0}^{1} \int_{0}^{1 / 2 n} V(z, \theta, \boldsymbol{x}, \boldsymbol{a}, \boldsymbol{p}) \mathrm{d} z \mathrm{~d} G(\theta)+p / n-C(a)-F \\
& =(k+\mathrm{E}(\theta) a) / n-(1 / 2 n)^{2}-c a^{2} / 2-F .
\end{aligned}
$$

It follows that the total surplus in an $n$-firm industry is

$$
S(n, a)=k+\mathrm{E}(\theta) a-n c a^{2} / 2-n F-1 /(4 n) .
$$

Maximization with respect to quality $a$ yields the optimal quality level for $n$ varieties:

$$
\tilde{a}(n)=\mathrm{E}(\theta) /(n c)
$$

After substitution of the optimal quality level $\tilde{a}(n)$, total surplus is

$$
S(n) \equiv S(n, \tilde{a}(n))=k-n F+\left(\mathrm{E}(\theta)^{2} / c-1 / 2\right) /(2 n),
$$

which is a concave function of $n$ for $c>2 \mathrm{E}(\theta) .{ }^{17}$ Maximization with respect to $n$ yields the optimal number of firms:

$$
n^{\mathrm{o}}=\left\{\left\lceil 1 / 4-\mathrm{E}(\theta)^{2} /(2 c)\right\rceil / F\right\}^{1 / 2},
$$

and the implied optimal level of quality

$$
a^{\mathrm{o}}=\tilde{a}\left(n^{\mathrm{o}}\right)=\mathrm{E}(\theta) /\left(n^{\mathrm{o}} \mathcal{C}\right)
$$

Theorem 2. The surplus maximizing market structure consists of $n^{\circ}=$ $\left\{\left[1 / 4-\mathrm{E}(\theta)^{2} /(2 c)\right] / F\right\}^{1 / 2}$ differentiated products located symmetrically $1 / n^{\circ}$ apart, all of quality level $a^{\circ}=\mathrm{E}(\theta) /\left(c n^{\circ}\right)$.

The opportunity of competition in quality, as well as the availability of precommitment in this strategic variable, creates a distortion in the number of varieties which far exceeds the distortion in the game without quality differentiation. The optimal number of differentiated products is smaller than the equilibrium numbers in both the three-stage and four-stage games. In fact, the ratios of the equilibrium numbers of products in both games to the optimal number are larger than 2:

\footnotetext{
${ }^{17}$ For very low costs of quality, $c<2 \mathrm{E}(\theta)$, total surplus, $S(n)$, is convex in $n$. Equivalently, the joint maximization of $S(n, a)$ in $n$ and $a$ has no interior solution. For the very low cost technology it is optimal to produce an infinite number of products of infinitely high quality.
} 


$$
\left.n^{4 \mathrm{~s}^{*}} / n^{\mathrm{o}}>n^{3 \mathrm{~s}^{*}} / n^{\mathrm{o}}=\left[1-\mathrm{E}(\theta)^{2} /(2 c)\right] /\left[1 / 4-\mathrm{E}(\theta)^{2} /(2 c)\right]\right\}^{1 / 2}>2,
$$

and they are declining in $c$ with $\lim _{c \rightarrow 1} n^{4 \mathrm{~s}^{*}} / n^{\circ}=\lim _{c \rightarrow 1} n^{3 \mathrm{~s}^{*}} / n^{\circ}=2$. In other words, as quality become more expensive, and less of it is utilized, the distortion in the number of products at equilibrium compared with optimality is reduced. In the limit, as the costs of improving quality go to infinity, the distortion in product diversity approaches the distortion of the circular model without variation of quality levels as analyzed by Salop (1979), where there are exactly twice as many firms at equilibrium than is optimal.

Corollary 4. The free market provides a larger number of varieties than is optimal, $n^{4 \mathrm{~s}^{*}}>n^{3 \mathrm{~s}^{*}}>n^{\text {o }}$, with the ratio of equilibrium to optimal number of varieties decreasing in the cost of quality but bounded below by 2 .

Now the equilibrium levels of quality are compared with the optimal one. For any fixed number of firms, the quality level in the three-stage game is optimal, $a^{*}(n)=\tilde{a}(n)$, as seen by comparing (8) with (22). The distortion in the level of quality is created from the divergence between the equilibrium number of firms and the optimal one. Since equilibrium quality is inversely related to the number of active firms, and there is an excessive number of varieties at equilibrium compared with optimality, it follows that quality is under-provided at equilibrium compared with optimality:

$$
a^{3 \mathrm{~s}^{*}}=\mathrm{E}(\theta) / c n^{3 \mathrm{~s}^{*}}<\mathrm{E}(\theta) / c n^{0}=a^{\mathrm{o}} .
$$

The level of quality in the four-stage game is even lower, as explained in the previous section and stated in Corollary 3, because precommitment allows a firm to achieve the same strategic leverage using a lower level of quality, and because there is a larger number of active firms compared with the three-stage game. Thus,

$$
a^{4 s^{*}}<a^{3 s^{*}}<a^{\mathbf{0}} .
$$

Corollary 5. The level of quality produced by each firm is higher at optimality than at the three-stage equilibrium, which is itself higher than the quality level of the four-stage equilibrium, $a^{\circ}>a^{3 \mathrm{~s}^{*}}>a^{4 \mathrm{~s}^{*}}$.

The ultimate criterion of a game structure is its contribution to social surplus. The realized surpluses at the equilibrium of the two-game structures are now compared. From eqs. (21) and (22b), $S(n, a)$ is the total surplus with $n$ active firms providing goods of quality $a$ and $S(n)$ is the total surplus with $n$ varieties and the corresponding optimal number of firms. Since there is no distortion in the level of quality for a fixed number of firms, the realized 
surplus at the equilibrium of the three-stage game, $S^{3 s}$, is equal to the optimal surplus for the same number of firms:

$$
S^{3 \mathrm{~s}} \equiv S\left(n^{3 \mathrm{~s}^{*}}, a^{3 \mathrm{~s}^{*}}\right)=S\left(n^{3 \mathrm{~s}^{*}}, \tilde{a}\left(n^{3 \mathrm{~s}^{*}}\right)\right) \equiv S\left(n^{3 \mathrm{~s}^{*}}\right)
$$

However, in the four-stage game, quality is under-provided for any number of firms, $a^{* *}(n)<\tilde{a}(n)$, because quality is used for strategic precommitment. In particular, $a^{4 s^{*}}=a^{* *}\left(n^{4 s^{*}}\right)<\tilde{a}\left(n^{4 s^{*}}\right)$. Therefore the realized surplus at the equilibrium of the four-stage game is lower than the optimal surplus for the same number of active firms:

$$
S^{4 \mathrm{~s}} \equiv S\left(n^{4 \mathrm{~s}^{*}}, a^{4 \mathrm{~s}^{*}}\right)<S\left(n^{4 \mathrm{~s}^{*}}, \tilde{a}\left(n^{4 \mathrm{~s}^{*}}\right)\right) \equiv S\left(n^{4 \mathrm{~s}^{*}}\right) .
$$

Since the surplus at the optimal quality level, $S(n) \equiv S(n, \tilde{a}(n))$, is concave and is maximized at $n^{\circ}$, where $n^{\circ}<n^{3 \mathrm{~s}^{*}}<n^{4 \mathrm{~s}^{*}}$, it follows that

$$
S\left(n^{4 \mathrm{~s}^{*}}\right)<S\left(n^{3 \mathrm{~s}^{*}}\right) .
$$

Combining eqs. (24a)-(24c) it follows that the surplus at the equilibrium of the four-stage game is lower than the surplus at the equilibrium of the threestage game, $S^{4 s}<S^{3 s}$. This is summarized in Theorem 4 .

Theorem 4. Precommitment in the level of quality reduces total surplus at equilibrium.

\section{Should there be a market for quality? The role of minimum quality standards}

The level of quality and the number of varieties provided by the market are substitutes. Ceteris paribus consumers prefer a higher level of quality and (in the aggregate) a larger number of varieties. Firms balance the provision of these desirable features taking into account the strategic role that they play in a non-cooperative equilibrium. In pure horizontal differentiation, a tendency has been observed for the provision of an excessive number of varieties compared with optimality [Salop (1979), Economides (1989a)]. This is because profits for a new variety are generated mainly from purchases from customers 'stolen' from other firms rather than from purchases of new customers. The addition of vertical differentiation to horizontal differentiation can, when quality is an aggressive strategic variable, facilitate attracting customers from other varieties. This results in an even bigger deviation of the free-entry equilibrium number of varieties from optimality. In these circumstances, a reduction of the number of firms through regulation of entry will increase the level of quality in the market and will be socially beneficial. 
Many times regulation of entry is infeasible. Here we can take advantage of the inverse relationship between the number of firms and the level of quality at equilibrium and recommend the use of minimum quality regulation instead of entry regulation. Setting a quality floor reduces the number of varieties at equilibrium. The fact that the number of firms at the free-entry equilibrium of this model is farther away from the optimal number than in the model of no quality variations of Salop (1979) (Corollary 4) suggests the possibility that setting a minimum quality standard may be welfareimproving. Thus, opening competition in the dimension of quality may not be welfare-improving.

Consider the present model with quality level fixed at an arbitrary level $\hat{a}$ for all firms, and let firms compete in three stages: in entry, variety choice, and price choice. The model now is a simplified version of the four-stage game of the previous section with quality choice eliminated. The analysis of the price subgame is identical to that of subsection 4.1 yielding equilibrium price [as in eq. (12)]

$$
p_{j}^{* *}=\sum_{i=-n / 2}^{n / 2} b_{1+|i|} e_{j+i}(\hat{a}, \boldsymbol{x}) .
$$

The realized profits at equilibrium are [as in eq. (13)]

$$
\Pi_{j}\left(p^{* *}(\hat{\boldsymbol{a}}, \boldsymbol{x}, n), \hat{\boldsymbol{a}}, \boldsymbol{x}, n\right)=\left(p_{j}^{* *}\right)^{2}-c\left(\hat{a}_{j}\right)^{2} / 2-F .
$$

In the preceding stage of the choice locations, firms use these equilibrium profits as their objective functions:

$$
I_{j}^{\mathrm{L}}(\boldsymbol{x}, n) \equiv \Pi_{j}\left(p^{* *}(\hat{\boldsymbol{a}}, \boldsymbol{x}, n), \hat{\boldsymbol{a}}, \boldsymbol{x}, n\right) .
$$

It is easy to show that there exists an equilibrium at symmetric locations $x_{j}^{* *}-x_{j-1}^{* *}=1 / n$, and implied equal prices. ${ }^{18}$ The equilibrium profits are

$$
\Pi_{j}^{\mathrm{L}}\left(\mathrm{x}^{* *}, n\right)=1 / n^{2}-c \hat{a}^{2} / 2-F .
$$

In the entry stage, firms enter until profits are zero. Thus, the equilibrium number of firms in this three-stage game with quality arbitrarily fixed at $\hat{a}$ is

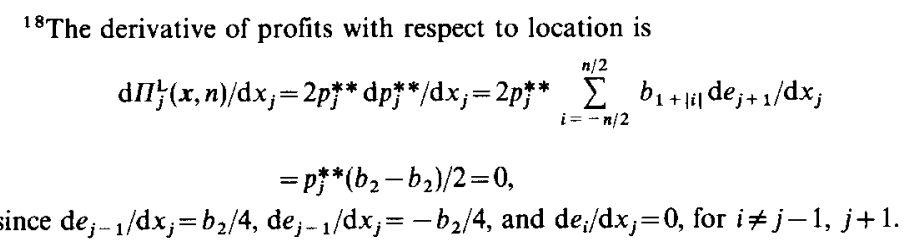




$$
n^{\mathrm{s}}(\hat{a})=1 /\left(F+c \hat{a}^{2}\right)^{1 / 2}
$$

The supcrscript ' $s$ ' is used for the equilibrium of this game because it is similar to the pure variety differentiation model of Salop (1979), which can be thought of as a special case of the quality-restricted model for $\hat{a}=0$.

Without quality competition, there are $n^{\mathrm{s}}(\hat{a})$ firms and total surplus $S\left(n^{s}(\hat{a}), \hat{a}\right)$. With quality competition in the three-stage game, there are $n^{3 \mathrm{~s}^{*}}$ active firms and corresponding surplus $S\left(n^{3 \mathrm{~s}^{*}}, a^{3 \mathrm{~s}^{*}}\right)$, and in the four-stage game where precommitment is possible we have $n^{4 \mathrm{~s}^{*}}$ firms and surplus $S\left(n^{4 \mathrm{~s}^{*}}, a^{4 \mathrm{~s}^{*}}\right)$.

The equilibrium profits in the unconstrained game, $S^{3 \mathrm{~s}} \equiv S\left(n^{3 \mathrm{~s}^{*}}, a^{3 \mathrm{~s}^{*}}\right)$, and the quality-constrained equilibrium surplus, $S\left(n^{\mathrm{s}}(\hat{a}), \hat{a}\right)$, are now compared for different levels of quality $\hat{a}$. It is easy to show that, when the level of quality is sct a priori at the equilibrium level $\hat{a}=a^{3 s^{*}}$, the realized total surplus is equal to the one of the equilibrium, $S\left(n^{\mathrm{s}}\left(a^{3 \mathrm{~s}^{*}}\right), a^{3 \mathrm{~s}^{*}}\right)=S\left(n^{3 \mathrm{~s}^{*}}, a^{3 \mathrm{~s}^{*}}\right)$. This is because $n^{\mathrm{s}}\left(a^{3 \mathrm{~s}^{*}}\right)=n^{3 \mathrm{~s}^{*}}$, as seen by substitution of (10b) in (25). Total surplus $S\left(n^{s}(\hat{a}), \hat{a}\right)$ is a concave function of the a priori set $\hat{a}$. Furthermore, total surplus is increasing at $\hat{a}=a^{3 \mathrm{~s}^{*}} \cdot{ }^{19}$ Therefore there exists a range of quality levels $A_{3}=\left(a^{3 \mathrm{~s}^{*}}, \bar{a}\right)$ such that for $\hat{a} \in A_{3}$ total surplus is higher when firms $d o$ not compete in quality, $S\left(n^{\mathrm{s}}(\hat{a}), \hat{a}\right)>S^{\mathrm{s}}\left(n\left(a^{3 \mathrm{~s}^{*}}\right), a^{3 \mathrm{~s}^{*}}\right) \equiv S^{3 \mathrm{~s}}$ (see fig. 3). A regulator picking minimum quality standards can improve over the market by picking a quality level $\hat{a} \in A_{\mathbf{3}}$.

Theorem 5. Opening competition in the specifications of qualities in a market where firms already compete in variety specifications and there is free entry can result in equilibria of lower total surplus than when competition in quality specification was not available. A regulator picking minimum quality standards can always improve total surplus over the market equilibrium.

Similarly, one can compare the realized surplus at the equilibrium of the four-stage game, $S^{4 \mathrm{~s}} \equiv S\left(n^{4 \mathrm{~s}^{*}}, a^{4 \mathrm{~s}^{*}}\right)$, with the surplus when quality is constrained at an arbitrary level $\hat{a}, S\left(n^{\mathrm{s}}(\hat{a}), \hat{a}\right)$. It can be shown that $S\left(n^{4 \mathrm{~s}^{*}}, a^{\mathbf{4} \mathrm{s}^{*}}\right)=$ $S\left(n^{\mathrm{s}}\left(a^{4 \mathrm{~s}^{*}}\right), a^{4 \mathrm{~s}^{*}}\right)$ so that $S^{4 \mathrm{~s}}$ intersects $S\left(n^{\mathrm{s}}(\hat{a}), \hat{a}\right)$ at $a^{4 \mathrm{~s}^{*}} . S\left(n^{\mathrm{s}}(\hat{a}), \hat{a}\right)$ is increasing at $a^{4 \mathrm{~s}^{*}}$ because it is concave and it is increasing at $a^{3 \mathrm{~s}^{*}}>a^{4 \mathrm{~s}^{*}}$, as has been shown above. Therefore there exists a region $A_{4}=\left(a^{4 s^{*}}, \overline{\bar{a}}\right)$ such that for all $\hat{a} \subset A_{4}$ total surplus is higher when firms do not compete in quality, $S\left(n^{\mathrm{s}}(\hat{a}), \hat{a}\right)>S^{4 \mathrm{~s}}$. Since $a^{4 \mathrm{~s}^{*}}<a^{3 \mathrm{~s}^{*}}$ and $S^{4 \mathrm{~s}}<S^{3 \mathrm{~s}}, A_{4}$ contains $A_{3}$ (see fig. 3). Therefore Theorem 5 also holds when the proposed opening of competition in quality levels takes the form of the four-stage game with quality precommitment, as described in section 3 .

${ }^{19}$ From $(21), S\left(n^{\mathrm{s}}(\hat{a}), \hat{a}\right)=k+\mathrm{E}(\theta) \hat{a}-(5 / 4)\left[F+c \hat{a}^{2} / 2\right]^{1 / 2}$. It follows that $\mathrm{d} S\left(n^{\mathrm{s}}(\hat{a}), \hat{a}\right) / \mathrm{d} \hat{a}=\mathrm{E}(\theta)-$ $(5 / 8) \hat{a} c /\left[F+c \hat{a}^{2} / 2\right]^{1 / 2}$, and $\mathrm{d}^{2} S\left(n^{\mathrm{s}}(\hat{a}), \hat{a}\right) / \mathrm{d} \hat{a}^{2}=-(5 / 8) c F^{1 / 2} /\left[F+c \hat{a}^{2} / 2\right]^{3 / 2}<0$. After substitution of $a^{3 \mathrm{~s}^{*}}=\mathrm{E}(\theta) F^{1 / 2} /\left\{c\left[1-\mathrm{E}(\theta)^{2} / 2 c\right]\right\}$, we have $\mathrm{d} S\left(n^{\mathrm{s}}\left(a^{3 \mathrm{~s}^{*}}\right), a^{3 \mathrm{~s}^{*}}\right) / \mathrm{d} \hat{a}=3 \mathrm{E}(\theta) / 8>0$. 


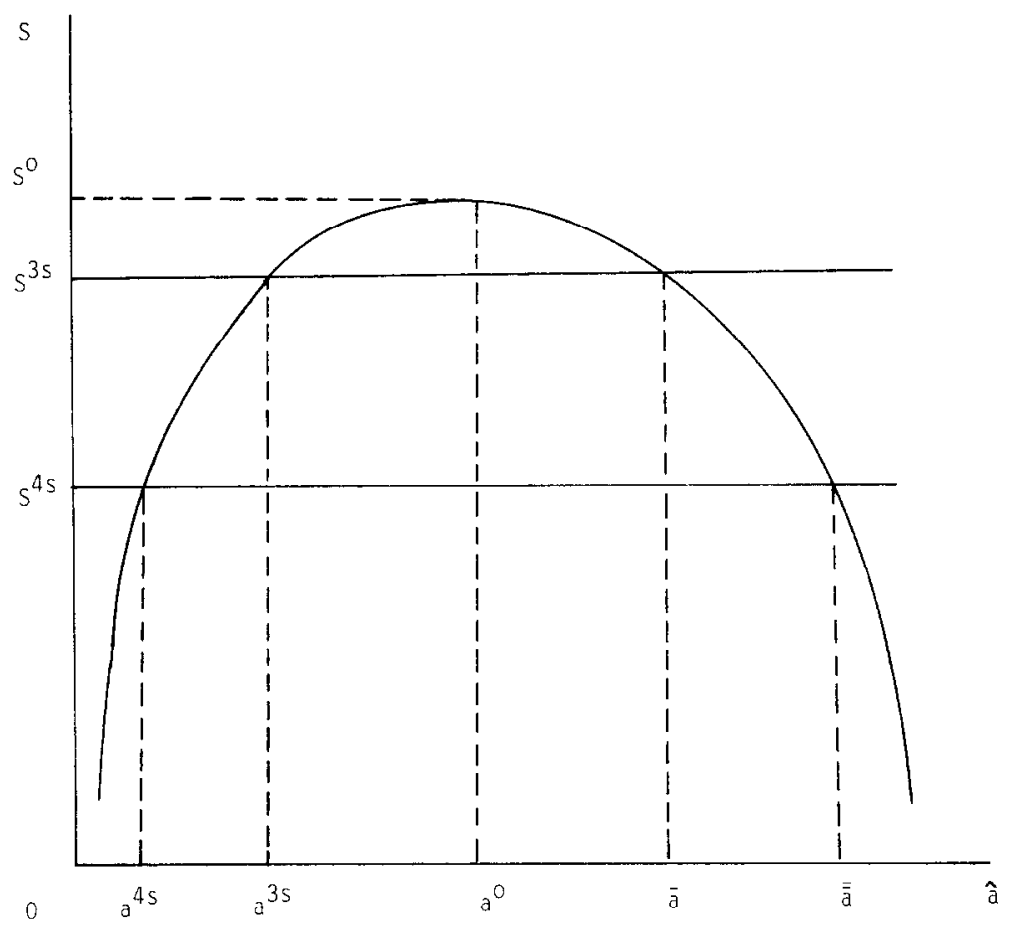

Fig. 3. Comparison of total surplus with fixed and variable quality levels.

\section{Concluding remarks}

It has been shown that the overcrowding of brands in the traditional circular model of variety-differentiated products is accentuated when the possibility of varying quality levels is introduced. At equilibrium, quality is under-provided compared with optimality. Both these adverse influences on total welfare are intensified when firms have the ability to precommit themselves on their quality level. Salop (1979) pointed to the fact that in a model of locationally differentiated products, profits did not signal correctly to potential entrants, and as a result there is excess diversity at the free-entry equilibrium. It has been shown herc that the addition of another dimension of competition in quality makes things even worse, with a larger distortion in the number of varieties and in total surplus. A limitation of competition through the introduction of precommitment in quality results in an increase in the number of varieties, a decrease in the level of quality, and a reduction in total surplus.

At equilibrium, the level of quality is inversely related to the number of varietites. It has been shown that the regulation of quality through the 
setting of minimum quality standards reduces the number of varieties and can be welfare-improving. Using similar reasoning it has been shown that opening competition in quality specification (with or without precommitment) can lead to equilibria of lower total surplus than when quality is fixed. Therefore opening competition in the quality dimension can be welfare-decreasing. ${ }^{20}$

\footnotetext{
${ }^{20}$ This last result is particularly important when seen in the context of trademarked goods. Trademarks provide an efficient way to distinguish between goods that are identical in their observable characteristics, but differ in their unobservable features. Thus, trademarks allow firms to compete in the unobservable features of their output. When such features are of the quality type, the introduction of trademarks allows for quality competition among variety-differentiated goods. It has been shown that opening such competition can be welfare-decreasing. Trademarks also allow for perception advertising in which a desired image is attached to variety-differentiated goods as described in footnote 1 . Thus, trademarks can open competition in another dimension of quality and that can again be welfare-decreasing. For a detailed analysis of perception advertising and its relationship to trademarks, see Economides (1988).
}

\section{References}

D'Aspremont, Claude, Jean Jaskold-Gabszewicz and Jacques-Francois Thisse, 1979, On Hotelling's Stability in competition, Econometrica 47, 1145-1150.

Economides, Nicholas, 1983, Symmetric oligopoly in differentiated products, Discussion paper no. 208 (Department of Economics, Columbia University).

Economides, Nicholas, 1986, Advertising in the circular model of differentiated products, Discussion paper no. 316 (Department of Economics, Columbia University).

Economides, Nicholas, 1987, On Nash equilibrium existence and optimality in oligopolistic competition in prices and varieties, Greek Economic Review 9, no. 2, 198-209.

Economides, Nicholas, 1988, The economics of trademarks, Trademark Reporter 78, 523-539.

Economides, Nicholas, $1989 \mathrm{a}$, Symmetric equilibrium existence and optimality in differentiated products markets, Journal of Economic Theory 47, no. 1, 178-194.

Economides, Nicholas, 1989b, Quality variations and maximal product differentiation, Regional Science and Urban Economics 19, 21-29.

Fudenberg, Drew and Jcan Tirole, 1984, The fat-cat effect, the puppy-dog ploy, and the lean and hungry look, American Economic Review 74, no. 2, 361-366.

Hotelling, Harold, 1929, Stability in competition, Economic Journal 39, 41-57.

Jaskold-Gabszewicz, Jean and Jacques-Francois Thisse, 1980, Entry (and exit) in a differentiated industry, Journal of Economic Theory 22, 327-338.

Lancaster, Kelvin, 1979, Variety, equity and efficiency (Columbia University Press, New York).

Mussa, Michael and Sherwin Rosen, 1978, Monopoly and product quality, Journal of Economic Theory 18, 301-317.

Nerlove, Marc and Kenneth Arrow, 1962, Optimal advertising policy under dynamic conditions, Economica 29, 9-42.

Neven, Damien and Jacques-Francois Thisse, 1990, On quality and variety competition, in J.J. Gabszewicz, J.-F. Richard and L.A. Wolsey, eds., Decision-making: Games, econometrics and optimization (North-Holland, Amsterdam) 175-199.

Novshek, William, 1980, Equilibrium in simple spatial (or differentiated) product markets, Journal of Economic Theory 22, no. 2, 313-326.

Salop, Steven, 1979, Monopolistic competition with outside goods, Bell Journal of Economics 10 , no. $1,141-156$.

Schmalensee, Richard, 1982, Product differentiation advantages of pioneering brands, American Economic Review 72, 349-365.

Shaked, Avner and John Sutton, 1983, Natural oligopolies, Econometrica 51, 1469-1484.

Waterman, David, 1990, Diversity and quality of information in a monopolistically competitive industry, Information Economics and Policy 4, 291-303. 